\title{
The Warsaw soundscape - structure and specifics
}

\begin{abstract}
The Warsaw soundscape has been examined according to the principles of acoustic ecology. The soundscape is the acoustic environment tested primarily by qualitative research. Warsaw residents were asked in a survey about their sound impressions and requirements for the Warsaw soundscape. The aim of this research was to learn both the conditions of acoustic environment and the needs of space users in accordance with the space category. The present and expected sound structures of five different categories of space were examined (residential areas, streets, city centre, tourist areas and green areas). Information on both the specific Warsaw sounds and the ideas for new sounds (which could be introduced into the city) was collected.
\end{abstract}

Keywords

Soundscape $\cdot$ acoustic environment $•$ Warsaw $•$ survey $\bullet$ specific sounds

(C) University of Warsaw - Faculty of Geography and Regional Studies

\author{
Małgorzata Romanowska \\ Department of Geoecology \\ Faculty of Geography and Regional Studies \\ University of Warsaw \\ e-mail: malgorzata.romanowska@student.uw.edu.pl \\ Received: 4 February 2014 \\ Accepted: 6 May 2014
}

Introduction

In Western culture, sight is the most important human sense, so in designing spaces, people focus on the visual character of their environment. This is the reason that over the centuries our sonic environment has become noisy and chaotic, especially in urban spaces. Nowadays, the surrounding sounds are unhealthy and have a significant negative influence on social life. Authorities have responded to the decrease in quality of sonic conditions with an act to fight noise pollution. For example, in the European Union, according to the Directive Relating to the Assessment and Management of Environmental Noise, each state member is obliged to create an action plan to reduce noise in places where the sound level exceeds standards and also to preserve quiet areas. However, an evaluation of the sonic environment should not be based only on quantitative indicators. That is why the concept of the soundscape and the field of acoustic ecology should be promoted.

Soundscape is a concept introduced by R. M. Schafer, who defined it as a sonic environment (Jespersen 2001). He treats it as a composition, a symphony of sounds. R. M. Schafer divided soundscapes into two categories: hi-fi (rural, quiet and harmonious) and lo-fi (urban and chaotic). He regards the postindustrial soundscape as lo-fi and characterizes it as the "Sound Wall" - uniform and monotonous (Wrightson 2000). Schafer clearly evaluates the urban soundscape negatively. Detlev Ipsen opposes Schafer's dualistic division into two soundscape categories. He proposes using Berlyne's hypothesis of the Complexity of Information and Motivation while interpreting the human reaction to a specific soundscape. The hypothesis says that the complexity of received information affects human motivation. The situation seems to be unattractive for individuals if the information is either not enough or too complex. Between those two states there is an optimal level, where the information is most motivating. Each person has an individual optimum level of information complexity. This model explains the diversity of people's opinions on the urban soundscape, interconnected with general principles.

The previous hypothesis does not explain the variety of reactions to soundscapes, depending on the context. That is why several research studies into human sound perception have been conducted. Brambilla \& Gallo (2013) studied human sound perception in urban parks in Rome. According to them, it is not only acoustical parameters that affect sound perception. They assumed that the presence of vegetation and natural sounds indicate soundscape quality. However, Berglung, Nilsson \& Axelsson (2007) carried out research in parks in Sweden and they assumed that the presence of nature or mechanical sounds is not crucial - the most important aspect is their domination. Accordance to them, pleasant soundscapes are those where human and nature sounds dominate and unpleasant soundscapes are dominated by mechanical sounds. They also created a model of perceived sound quality. As stated in their research report, soundscapes dominated by human sounds are perceived as pleasant and eventful (exciting) and those dominated by nature sounds are pleasant and uneventful (relaxing). Unpleasant soundscapes are dominated by mechanical sounds and they can by eventful (chaotic) or uneventful (boring).

There are many factors affecting human sound reception. Zhang \& Kang (2007) claim that under a certain level of sound 
pressure, human perception of soundscape quality does not correlate with loudness. Cain et al. (2008) created four categories of factors affecting the perception of soundscapes:

- demographics,

- current activity and listening state,

- temporal factors,

- spatial factors.

Nielbo, Steele \& Guastavino (2013), according to previous research, put forward the hypotheses that people rate soundscapes through activities. They investigated if and how the urban soundscape may be understood through affordances ("actionable properties of an object"). Participants listened to recordings of specific urban soundscapes and had to rate how appropriate they are for realizing specific activities. The research indicates that expectations of the soundscape differ and depend on activity categories. Collected verbal data also indicate that the soundscape is most often perceived in the context of space and events.

The most inspiring studies in the field were those carried out by Guastavino (2006) and López Barrio \& Carles (1995). The first studied how people rate urban soundscapes. Questionnaires with openended questions were sent by mail. The research indicates that people generally prefer nature sounds and do not like mechanical sounds. Human sounds are rated rather positively, with ratings depending on the emotional context. Moreover, in López Barrio \& Carles' (1995) study of the soundscapes of Madrid, they noticed that the evaluation of soundscapes depends on the degree of fulfilment of requirements for the sound structure and those requirements change in different space categories.

These two findings were relevant for constructing the base hypothesis for this research: that people change their requirements for soundscapes depending on the spatial context and with respect to general preferences (indicated in the Guastavino research). These findings seemed to be crucial to set goals of soundscape management.

Living in Warsaw, the author has noticed that sound management in this city focuses on noise reduction. Making sounds pleasant for users should be the primary aim of sound management in cities. This is why qualitative evaluation should be based on human opinion and should be taken into consideration in sound design. Warsaw is the largest city in Poland, so it is important to introduce innovative methods which improve living conditions. This is why in 2013 the survey was carried out to investigate the opinions of Varsovians about the structure of the Warsaw soundscape and specific Warsaw sounds. For the purposes of this work, the soundscape structure consists of sounds heard in a given place and time, divided by source. The author assumed that structure changes according to the space category. The main aim of the survey was to examine how expectations of the soundscape change in different types of urban spaces. The long term goal of this study is to show new opportunities for soundscape management (in comparison to noise reduction).

\section{Methods}

\section{Questionnaire}

The questionnaire begins with a general open-ended question about the sounds of Warsaw to collect data unbiased by the survey. There are then two closed-ended questions about terms which are associated and which should be associated with the Warsaw soundscape. The next 10 questions relate to the sound structure of the Warsaw soundscapes in different types of places. There are two closed-ended questions for each of the space categories: the first is about present sounds and the second about wanted and unwanted sounds. Urban spaces were classified into 5 categories: residential, streets, city centre, tourist and entertainment areas, and open spaces. The next four questions are about specific sounds and suggestions for new specific sounds which could be introduced into the city. The last questions ask for personal data.

\section{Procedures}

The questionnaire was published on the Internet from $3^{\text {rd }}$ to $22^{\text {nd }}$ March 2013 using a Google Form. The WWW address was distributed through social networks and forums.

\section{Respondents}

113 respondents answered -27 women, 86 men. $6 \%$ of them were under 18 years of age, $34 \%$ were aged between 18 and 25 , $50 \%$ between 26 and $35,6 \%$ between 36 and 45 , and $4 \%$ were older than 46 . They were Warsaw residents $-60 \%$ for more than 20 years, $19 \%$ for between 11 and 20 years, $21 \%$ for less than 10 years. The number of years lived in the city did not affect the results.

Results

Warsaw soundscape - general opinion

Results are based on answers to three questions from the survey:

1. What do you think about Warsaw sounds?

2. Which terms would you associate with the Warsaw soundscape?

3. Which terms SHOULD be associated with the Warsaw soundscape?

104 answers for the first of these questions were collected. In answering, respondents described attributes of the soundscape, their impressions, the nature of sounds and their sources. 9 people did not respond this question and one person answered "nothing". To interpret answers, a semantic analysis was carried out. Firstly, the meaning of words was analysed. Emotionally charged words and terms were collected and divided into two categories: negative and positive. The following words and terms were recognized as emotionally negative: "noise", "clamour", "loud", "loudly", "bedlam", "aggressive", "irritating", "unpleasant", "too much", "horrible", "chaos", "cacophony", etc. Terms like "pleasant", "poetic", "a pleasure for the ear", "to love", "to like", "the best" were marked as positive. In 43 cases this level of analysis was sufficient and adequate: words or terms did not form sentences. 41 of them had negative meaning and two of them were positive. 22 answers had no emotionally charged words.

Next, sentences and full texts were analysed. There were 44 answers formulated with one sentence. 16 were short statements. At this stage 8 answers containing pejorative words and terms were decisively recognized as negative. 3 responses were categorized as positive though pejorative words were used in the sentences ("noise", "chaotic", "loudly"): respondents claimed that they loved or liked Warsaw sounds either in spite of or even because of their loudness, chaos and noise. At this level of analysis, none of the 22 answers without emotionally charged words showed emotional content. There were 20 undecided responds: both positive and negative opinions appeared in a single text, neither of them dominating. In some answers judgments depended on the specificity of place and time.

In summary, 48 answers were categorized as negative, 13 as positive, 20 as mixed and 22 as having no opinion. 10 respondents did not answer this question (including one answer "nothing"). Next, the correlation between the number of years lived in the city and the created evaluation categories was examined. There is no statistical dependence between these two variables.

The most frequently mentioned sound sources were (Fig. 1): car (mentioned 22 times), tram (8), street (8), people (6), move (5), bird (4), children (3), transport (3), ambulance (3), police (3), street 


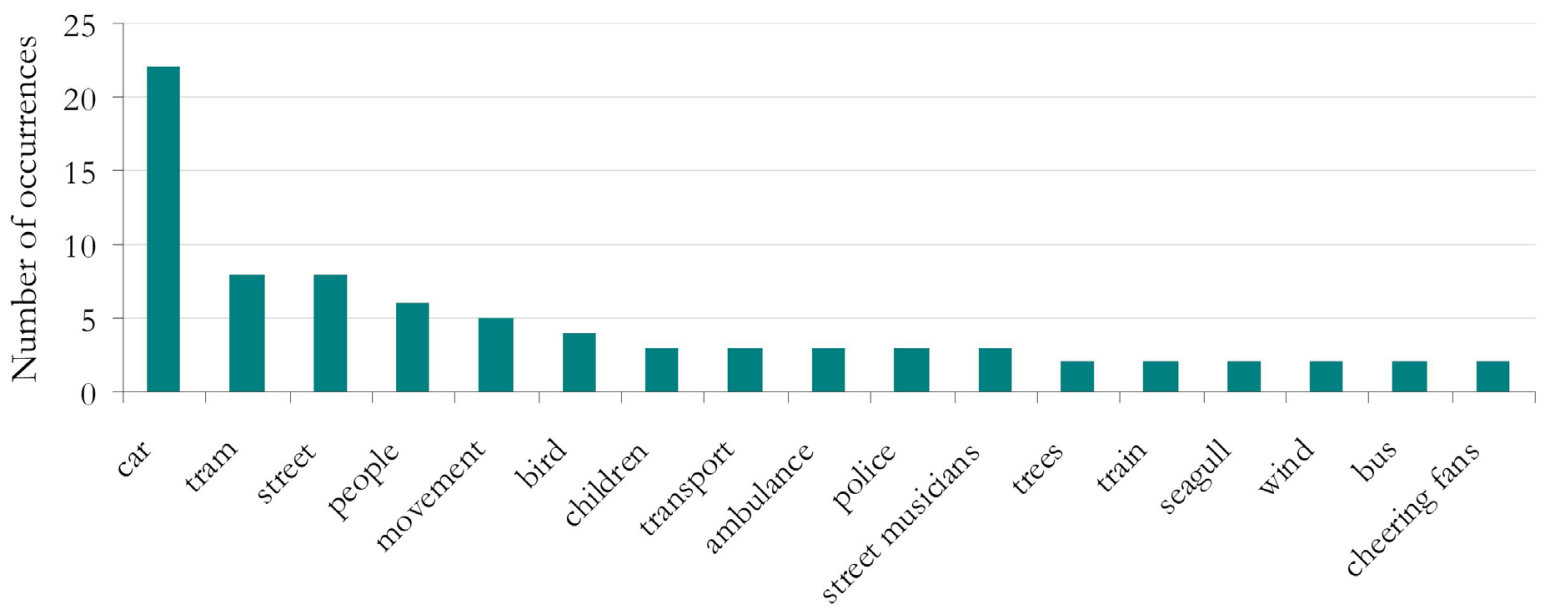

Figure 1. Warsaw sound sources spontaneously mentioned by respondents, on the basis of the survey in Warsaw

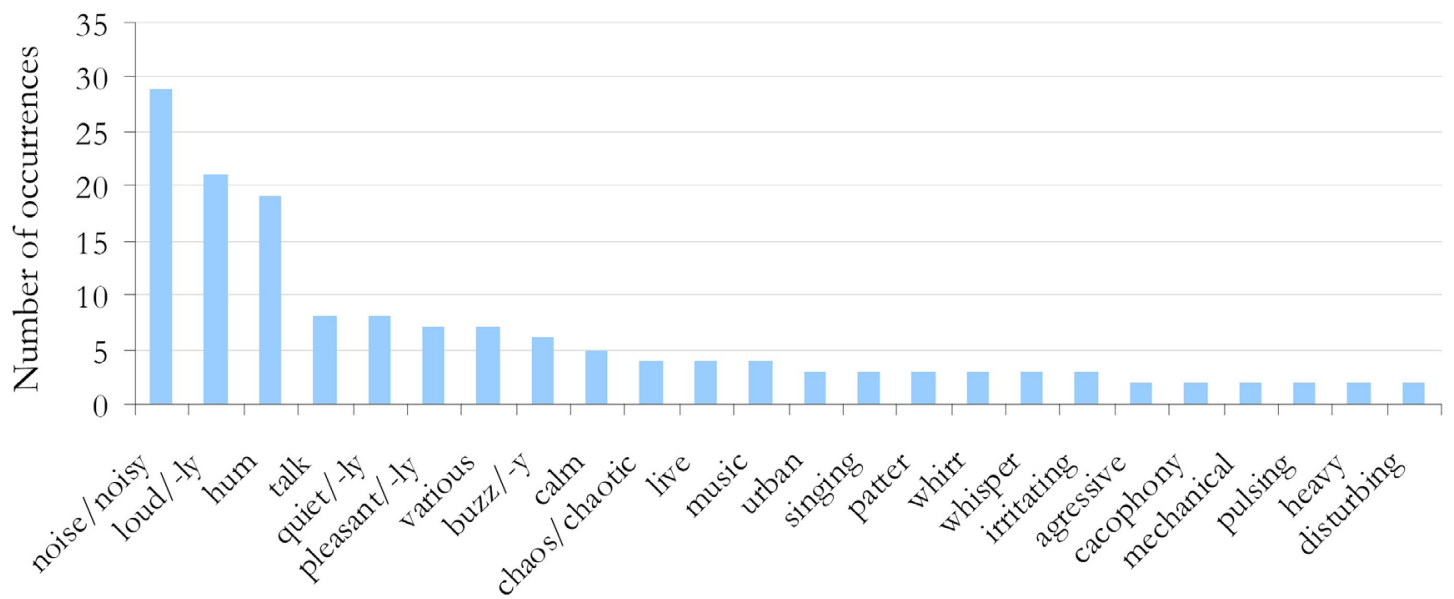

Figure 2. Terms describing the nature of Warsaw sounds spontaneously mentioned by respondents, on the basis of the survey in Warsaw

musicians (3), trees (2), train (2), seagull (2), wind (2), bus (2), and cheering fans (2). Other mentioned sources were: car alarm, bell, Chopin's piano, traffic, the current of the Vistula River, construction and road works, dogs, mobile phone, transit, and subway.

The most frequently mentioned terms describing the nature of sounds (Fig. 2) were noise/noisy (mentioned 29 times) and similar words like loud/loudly (21), cacophony (2), and clamour (1). Among others were: hum (19), talk (8), quiet/quietly (8), pleasant/pleasantly (7), various (7), buzz/buzzy (6), calm (5), chaos/chaotic (4), live (4), music (4), urban (3), singing (3), patter (3), whirr (3), whisper (3), irritating (3), aggressive (2), mechanical (2), pulsing (2), heavy (2), and disturbing (2). Others mentioned were: mumbling, tweet, suffocating, din, bang, intense, uniform, climate, arguing, lazy, sudden, insistent, unceasing, breath, terrible, squeaky, stimulant, mixed, repetitive, sentiment, familiar, signal, bark, laughter, difficult to identify, cute, lulling, metropolitan, ubiquitous, howl, tumult, variables, ordinary, liveliness.

The following human sounds were recollected: buzz, laugh, talk, baby shouts and cries, music of street performers, patter of high-heels, fans cheering, and night club sounds. Respondents mentioned such nature sounds as bird songs, rustle of leaves, sound of water, and wind. They indicated several mechanical sounds: car, tram and bus sounds, jarring of train, traffic hum, emergency vehicle sirens (police and ambulance), car alarm, construction and road works, crane signal, and transit.

In Figure 3 words are listed which were attributed with emotionally charged terms (positive and negative). There were not many sounds with individual opinions (mostly respondents judged the whole Warsaw soundscape). Because of the small number of occurrences, only tentative conclusions can be drawn. There were no nature sounds with negative opinions. Wind, hum of trees, bird sounds (including seagulls) and water sounds are quite favourable elements of the Warsaw soundscape. Opinions about human sounds were mixed. Music was poorly rated - either from technical devices or played by street musicians. Judgments of mechanic sounds were extremely various. Motors and cars are rather unpleasant. Sounds of public transport (trams, buses, trains) are liked. Traffic sounds (rather treated as a hum) were recognized as positive.

Some answers had almost a poetic style, describing nuances, nostalgic sounds and compositions, e.g.:

"It's a symphony, composed according to a place, where I actually am. There are small sonatas for the seagull's cry 


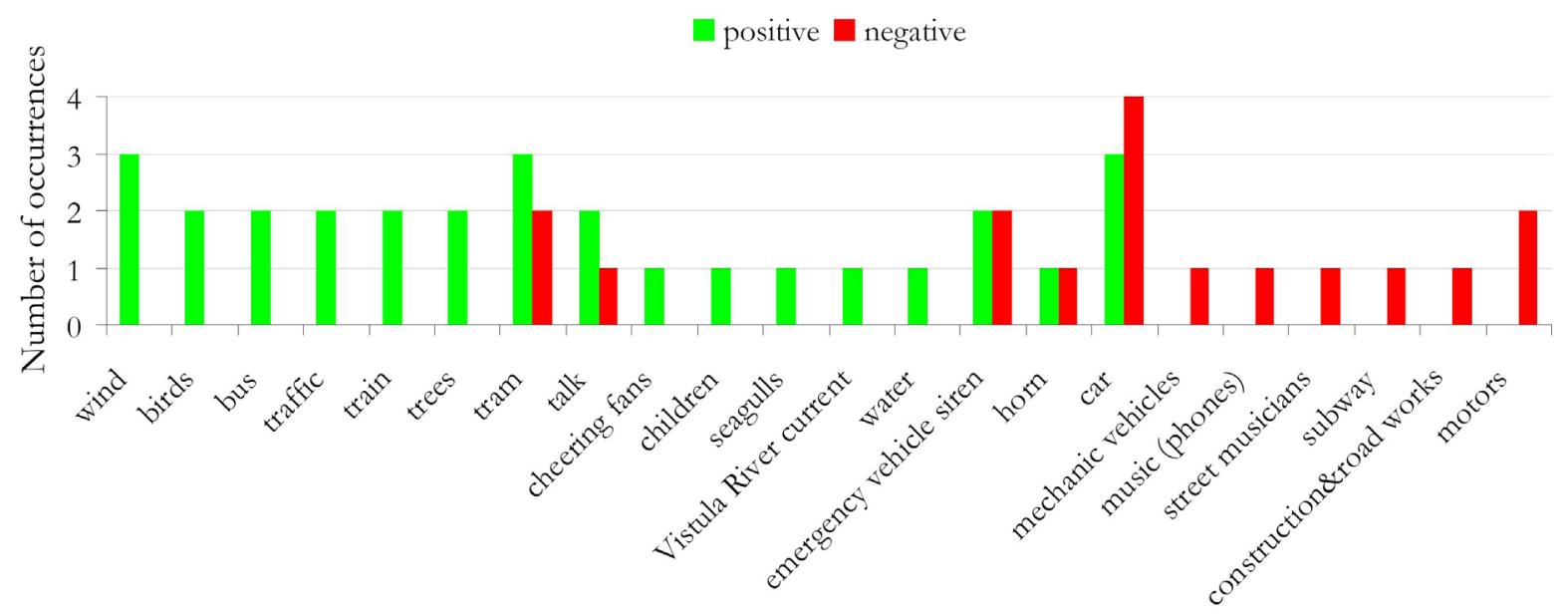

Figure 3. Spontaneous terms describing the Warsaw soundscape and judgments about them, on the basis of the survey in Warsaw

$$
\text { not associated } \square \text { neutral } \square \text { associated }
$$

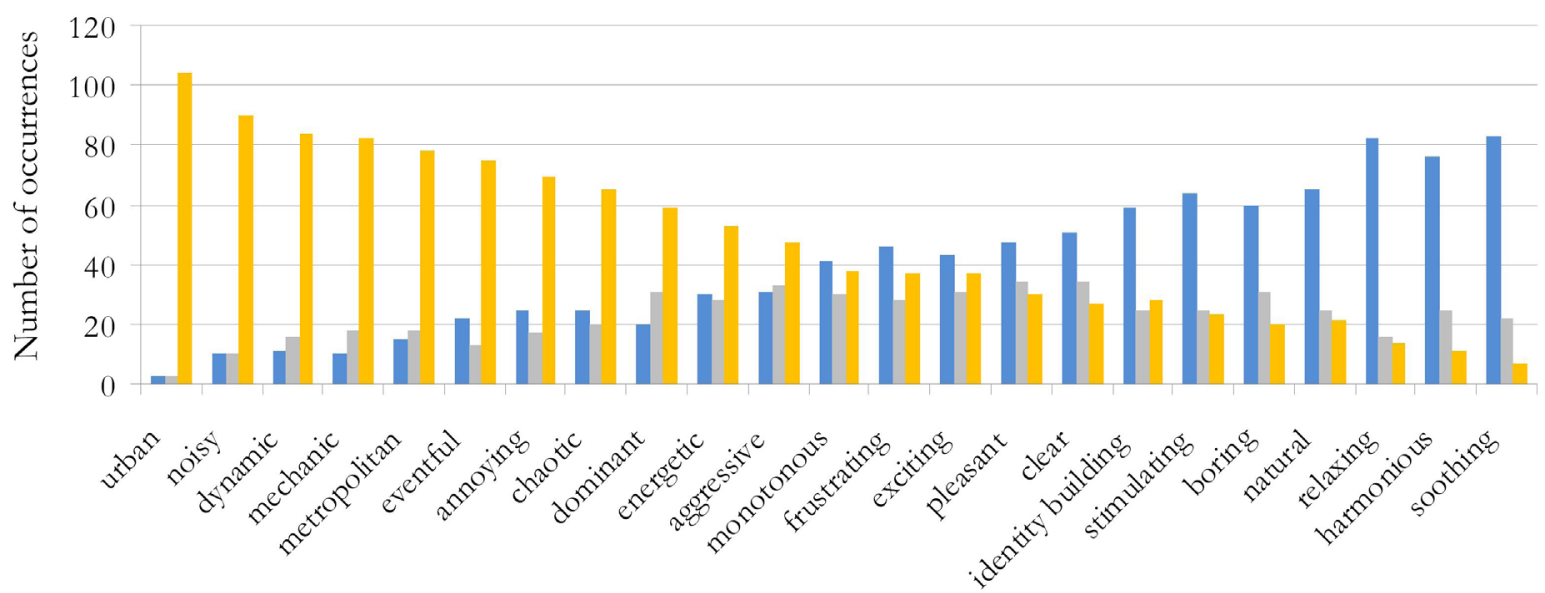

Figure 4. Terms associated with the Warsaw soundscape, on the basis of the survey in Warsaw

and wind near Gocław's tower blocks, euphonious murmurs of Ursynów's cafes. And also sounds, strong dynamic symphonies of tram and bus assaults, disrupted by quarrelling car horns, singing ambulances and police convoys going to a football match."

The next question of the survey was "Which terms would you associate with the Warsaw soundscape?" There were 23 words (Fig. 4) listed and the respondents had to answer on a scale of 1--5 (1 - strongly not associate, $2-$ not associate, 3 - neither associate nor not associate, 4 - associate, 5 - strongly associate). The words were chosen in a few ways. Firstly, terms directly describing urbanity were collected (urban, metropolitan), then words describing the harmony of a sound composition (chaotic, harmonious). Also chosen were words categorising sources (natural, mechanic), specifying the ease of orientation (clear) and impact on identity (identity building). There were also words related to Berglund, Nilsson \& Axelsson's (2007) model (eventful, noisy, annoying, frustrating, monotonous, soothing, relaxing, stimulating, exciting, boring, dynamic, energetic, pleasant, dominant). Finally, the list was compared with words which appeared in Guastavino's research report (Guastavino 2006) - the term "aggressive" was added - others had already been picked out.

The results are shown in Figure 4. More than $50 \%$ of respondents associate the Warsaw soundscape with the following terms: urban (104 occurrences), noisy (90), dynamic (84), mechanic (84), metropolitan (78), eventful (75), annoying (69), chaotic (65), and dominant (59). In Varsovians' opinions four of these terms - urban (90 occurrences), dynamic (83), metropolitan (86), eventful (90) - should be strongly associated with Warsaw (Fig. 5, answers to the question "Which terms should be associated with the Warsaw soundscape?" - the scale of 1-5 was changed into a 1-3 scale - answers 1 and 2, 4 and 5 were put together; also, the category of answers "neither should nor should not" was called "neutral" in Figure 5 to be more clear). The following terms are not associated with Warsaw, but in the respondents' opinion they should be associated: soothing ( 83 respondents do 
should not associate $\square$ neutral $\square$ should associate

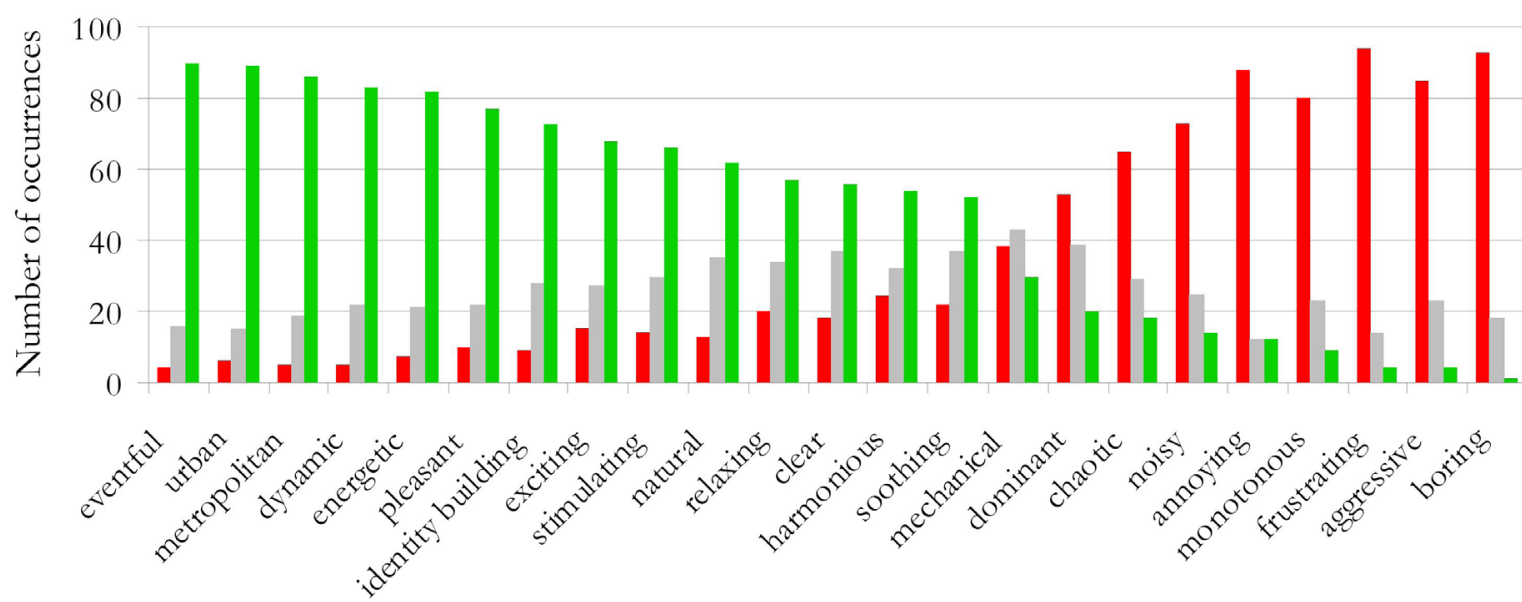

Figure 5. Classification of terms of the urban soundscape, on the basis of the survey in Warsaw

not associate this term with Warsaw; 52 consider that it should be associated with the city), harmonious (respectively: 76 ; 54 ), relaxing $(82 ; 57)$, natural $(65 ; 62)$, stimulating $(64 ; 66)$, and identity building $(59 ; 73)$.

\section{The structure of Warsaw soundscapes vs. ideal soundscapes}

The next part of the survey was about the soundscape structure in various urban spaces (residential, streets, city centre, tourist and entertainment areas, and open spaces). The respondents had to answer which of the listed sounds are present in those spaces and which of them should be present. The following questions were asked:

4. Which sounds can you hear each day in your residential area?

5. Please rate, on a scale of 1-5, if the listed sounds should be present in your residential area.

6. Which sounds can you hear on the street?

7. Please rate, on a scale of 1-5, if the listed sounds should be present on the street.

8. Which sounds can you hear in tourist and recreational areas?

9. Please rate, on a scale of 1-5, if the listed sounds should be present in tourist and recreational areas.

10. Which sounds can you hear in the city centre?

11. Please rate, on a scale of $1-5$, if the listed sounds should be present in the city centre.

12. Which sounds can you hear in open spaces?

13. Please rate, on a scale of $1-5$, if the listed sounds should be present in open spaces.

The list of sounds was the same in each of the 10 questions. The following sounds were used: bird songs, rustle of leaves, wind, human steps, human talk, children's shouts, music from technical devices, performed music, dog barking, horn, car alarm, emergency vehicle sirens, tram sounds, car sounds, scooter/ motorcycle sounds, bus sounds, aircraft sounds, sounds of construction work, sounds of road works, slamming doors/gates/ intercom sounds. Most of the sounds were collected depending on the author's other research carried out in Warsaw, based on the soundwalking method (Romanowska 2006). Others (like the music of street musicians and the sound of road works) were added on the basis of Guastavino's survey (Guastavino 2006).
The first two questions were "Which sounds can you hear each day in your residential area?" and "Please rate, on a scale of 1-5, if the listed sounds should be present in your residential area." The first question was a multiple choice question - respondents could select as many answers as they wanted. Answering the second question, respondents had to rate on a scale of 1-5 (1strongly should not, 2 - should not, 3 - neither should nor should not, 4 - should, 5 - strongly should) each of the listed sounds. The same scheme was used in the next 8 questions. In Figures 7 , $9,11,13,15$, the scale of $1-5$ was changed into a $1-3$ scale (the answers 1 and 2, 4 and 5 were put together). Also, the category of answers "neither should nor should not" was called "neutral" in the Figures, to be more clear.

More than $50 \%$ of respondents answered that in residential areas they hear the following sounds (Fig. 6): car sounds (91 occurrences), dog barking (91), wind (89), human talk (89), human steps (84), children's shouts (82), bird songs (72), emergency vehicle sirens (74), slamming doors/gates/intercom sounds (67), car alarm (67), and scooter/motorcycle sounds (68). The most frequently selected unwanted sounds are car sounds (58 respondents do not want to hear them in residential areas), as well as car alarm (83) and scooter/motorcycle sounds (58) as seen in Figure 7. Nature sounds are both wanted and present - like bird songs (108 respondents want them) or wind (85) and human sounds - like talking (73), steps (77), and children's shouts (72). More than $50 \%$ of respondents answered that the sounds that should not be heard in residential areas are those of construction and road works (88 and 86 occurrences), car alarm (83), horn (82), aircraft (81), tram (71), bus (67), car (58) and scooter/motorcycle (58) sounds.

The next two analogous questions were about streets. The following sounds were selected as heard on the street by more than $50 \%$ of respondents (Fig. 8): car sounds (111 respondents), human talk (105), emergency vehicle sirens (100), horn (96), tram (94), scooter and motorcycle sounds (92), dog barking (71), wind (69), car alarm (68), children's shouts (68), construction (60) and road work (58) sounds. The sounds that are wanted and present human talk (99 respondents want them), wind (85), children's shouts (73) and tram sounds (44) - Figure 9. Strongly wanted sounds (Fig. 9) are bird songs (99), human talk (99) and steps (97), rustle of leaves (95), wind (85), and children's shouts 


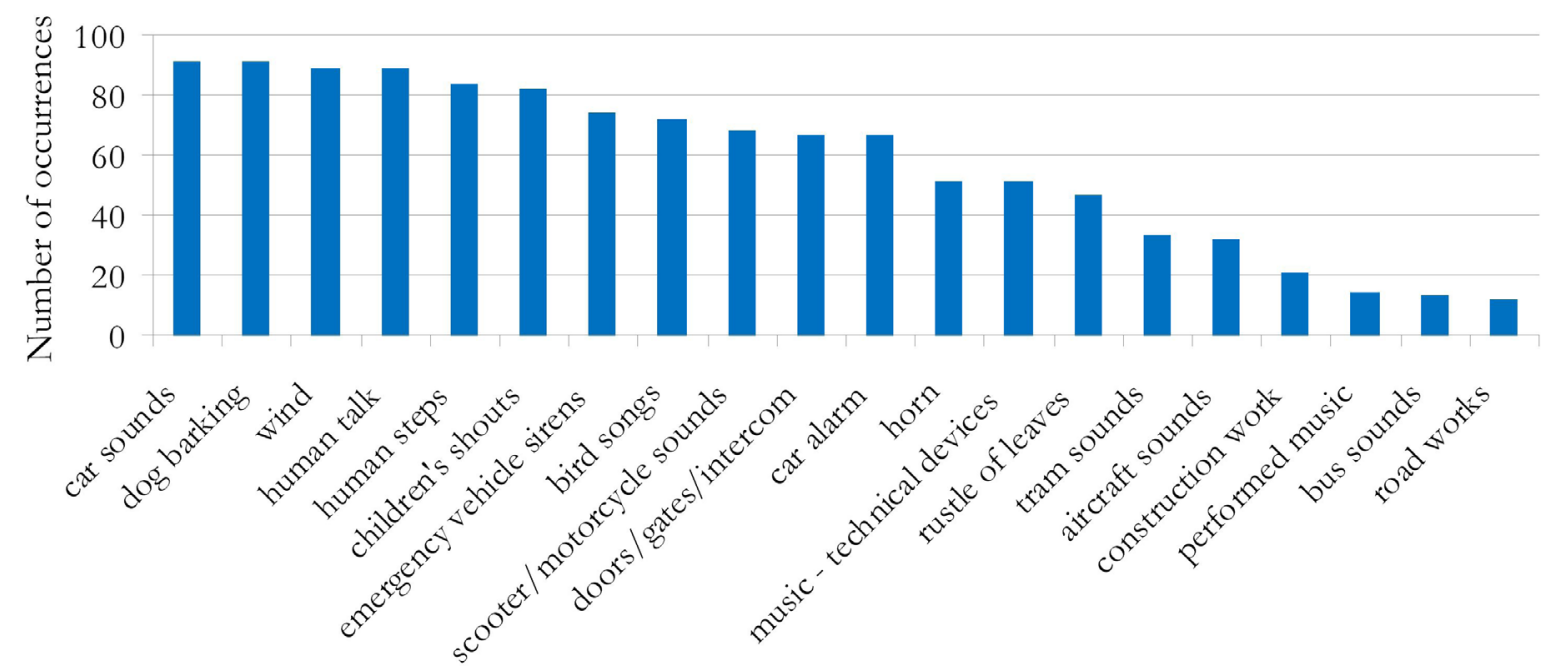

Figure 6. Sounds heard in residential areas, on the basis of the survey in Warsaw

should not neutral $\quad$ should

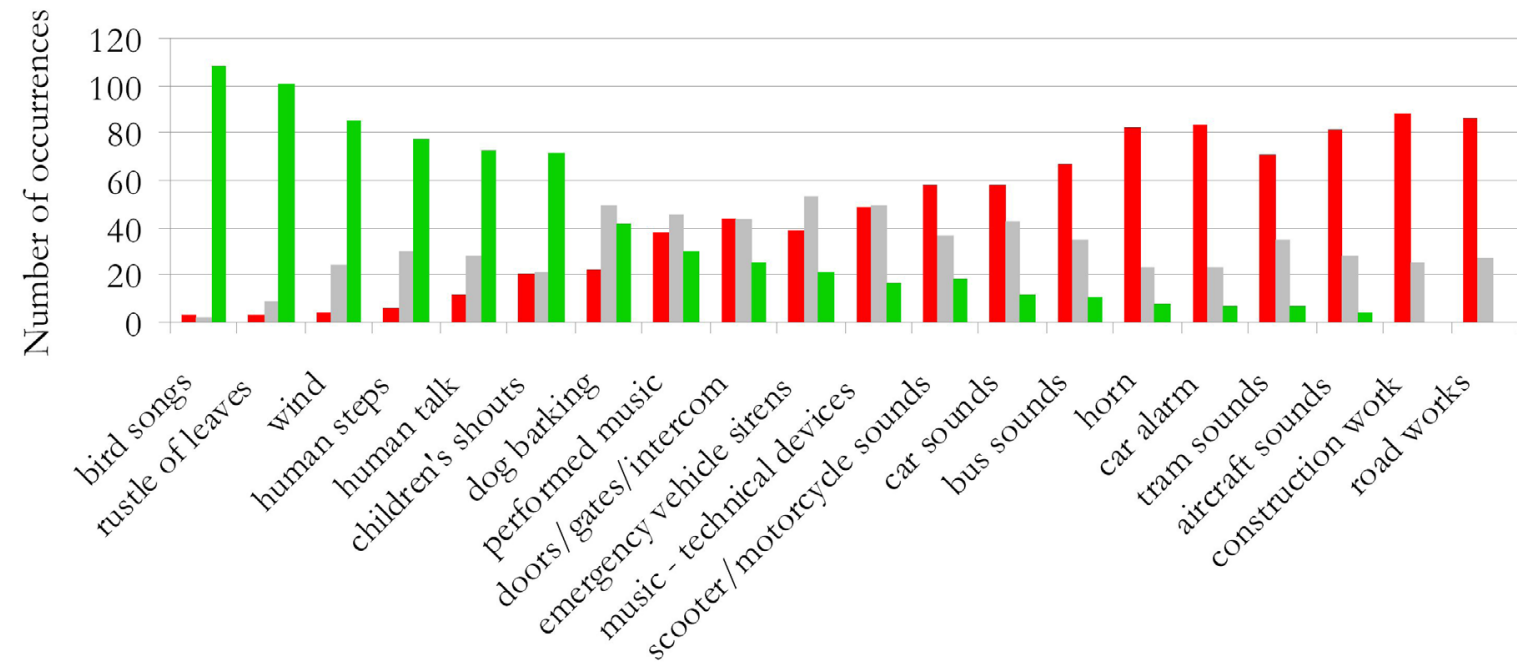

Figure 7. Classification of typical sounds in residential areas, on the basis of the survey in Warsaw

(73). There are only three strongly unwanted sounds: car alarm (63), construction (60) and road work (60) sounds.

It should be noted that transportation sounds have quite high, neutral ratings (Fig. 9). This is probably because of expectations people associate these sounds with street conditions. Moreover, in Figure 9 there is no such rate polarization as in Figure 7. This means that people have a greater tolerance for street than for residential soundscapes.

The next two questions concerned tourist and recreational areas. More than half of the respondents claimed that in those areas the following sounds are present (Fig. 10): human talk (110 occurrences) and steps (107), performed music (105), children's shouts (87), car sounds (70), wind (68), and emergency vehicle sirens (60). All of them (except car sounds and emergency vehicle sirens) are wanted.

More than $50 \%$ of respondents want the following sounds to be present in tourist and recreational areas (Fig. 11): bird songs (99 respondents), human talk (99) and steps (100), rustle of leaves (95), wind (85), performed music (81), and children's shouts (72). They do not accept sounds like (Fig. 11): construction (96 respondents) and road work sounds (96), car alarm (96), aircraft sounds (89), horn (95), scooter, motorcycle (84) and car sounds (84), slamming doors/gates/intercom sounds (68), tram (80) or bus sounds (74).

Despite the streets case (Fig. 9), rates of ideal sounds in tourist and recreational areas (Fig. 11) are polarized - only three sounds from the list (music from technical devices, dog barking, emergency vehicle sirens) were neither clearly judged as wanted or unwanted. The shape of Figure 11 is similar to Figure $7-$ this means that those space categories have a similar function.

Figures 12 and 13 show the results of the next questions, about the city centre. More than half of the respondents claim that the following sounds are present in the city centre: car (108 occurrences) and tram sounds (108), emergency vehicle sirens 

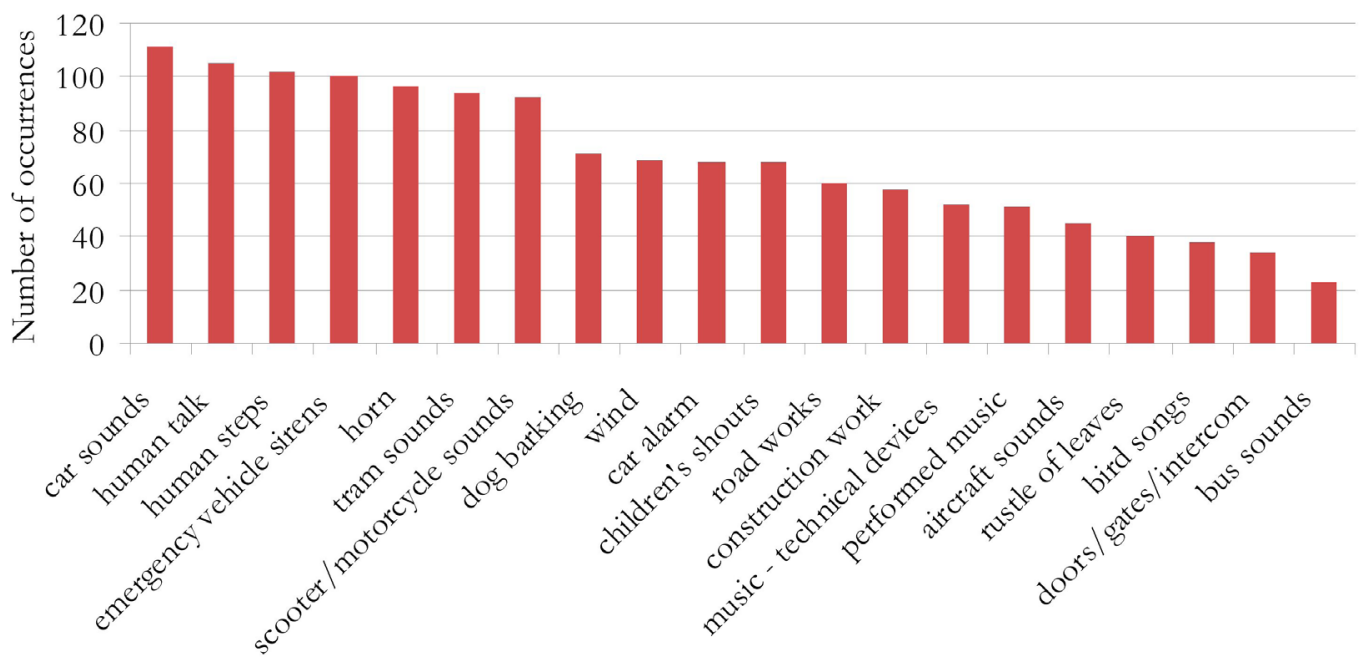

Figure 8. Sounds heard on the street, on the basis of the survey in Warsaw

should not neutral $\square$ should

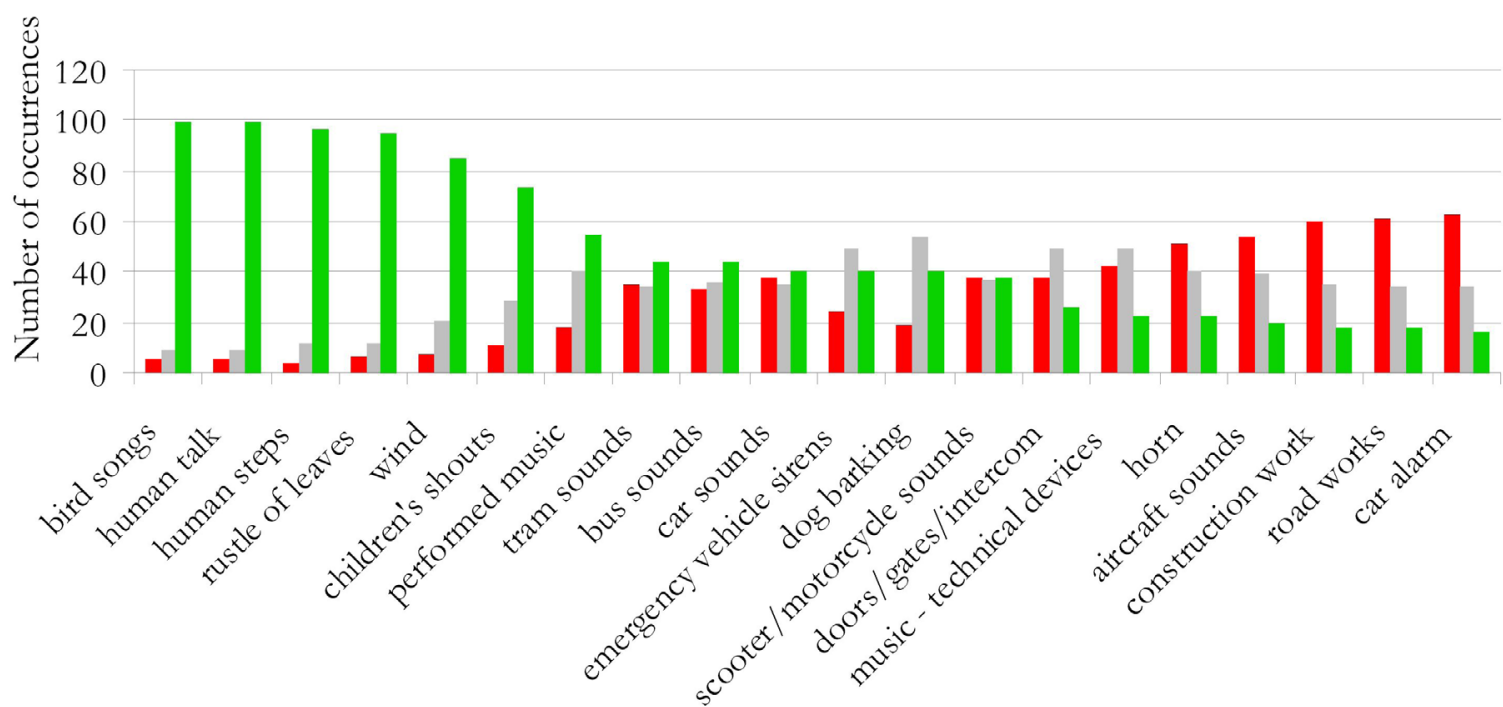

Figure 9. Classification of typical sounds on the street, on the basis of the survey in Warsaw

(107), scooter and motorcycle sounds (107), human talk (104) and steps (100), horn (100), car alarm (90), construction (85) and road work (90) sounds, performed music (81), music from technical devices (72), and children's shouts (67). Among these, the unwanted sounds are horn (42 respondents), car alarm (45), construction (44) and road work (43) sounds, and music from technical devices (39 - the rate of the last one is not clearly negative).

As Figure 13 shows, the sounds clearly wanted in the city centre are human talk (102 occurrences) and steps (94), children's shouts (70), performed music (69), bird songs (67), rustle of leaves (66), wind (65), tram (64), bus (60) and car (60) sounds. There are no sounds which more than $50 \%$ of respondents do not want to hear in the city centre. It is worth noting that this is the only space category where bird songs rank only fifth in the list. This demonstrates the flexibility of requirements associated with special living conditions in metropolises. Furthermore, the centre plays a major role in creating the metropolitan character of the city. This is why the soundscape should be exciting, full of human sounds and even (generally unpleasant) transport sounds.

The last two questions in this part of the survey were about open spaces. More than half of the respondents answered that in open spaces there are such sounds as (Fig. 14): rustle of leaves (111 occurrences), bird songs (111), wind (110), human talk (92), children's shouts (91), dog barking (91) and human steps (83). All of those sounds are wanted (Fig. 15). More than $50 \%$ of respondents claimed that the sounds that should be heard are bird songs (111 respondents), rustle of leaves (111), wind (107), human talk (83), children's shouts (65) and those that should not be heard are slamming doors/gates/intercom sounds (95 respondents do not want to hear these sounds), road (105) and construction work (105) sounds, aircraft sounds 

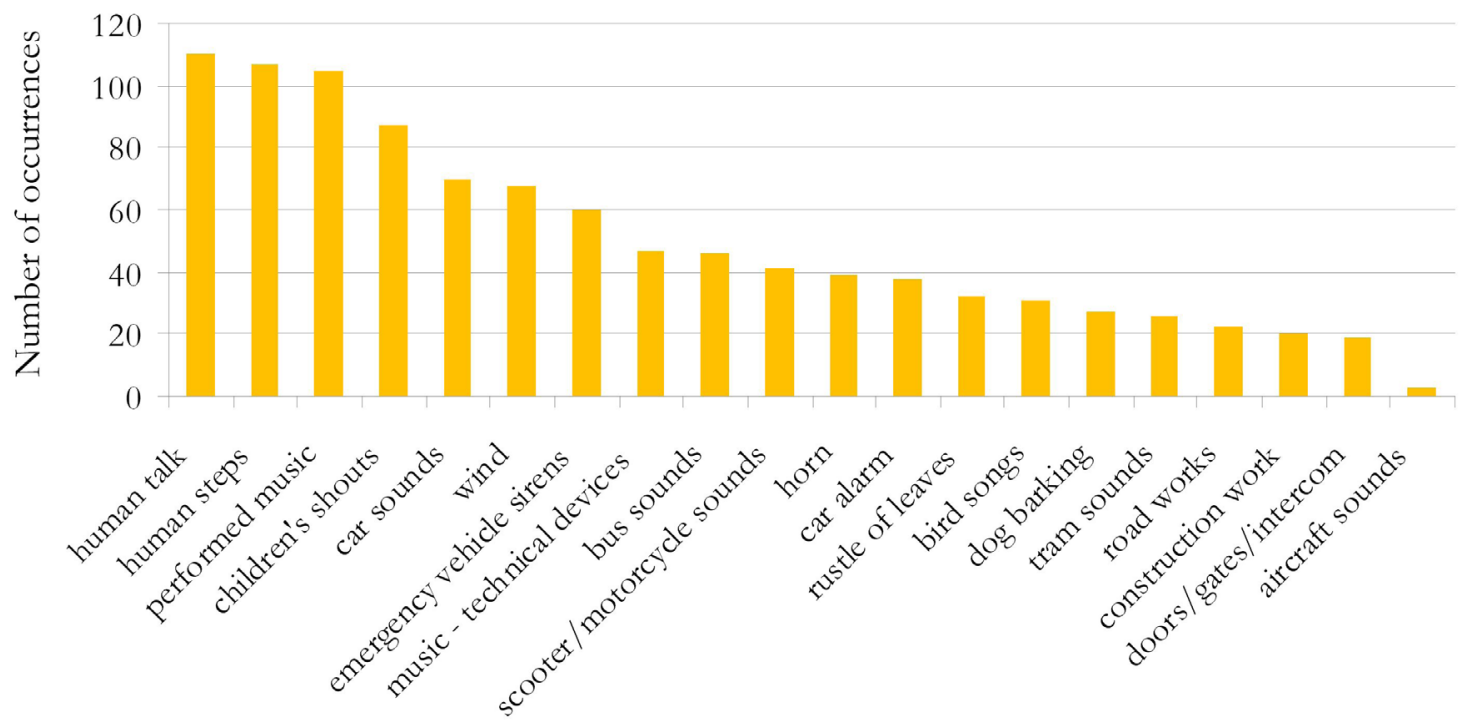

Figure 10. Sounds heard in tourist and recreational areas, on the basis of the survey in Warsaw

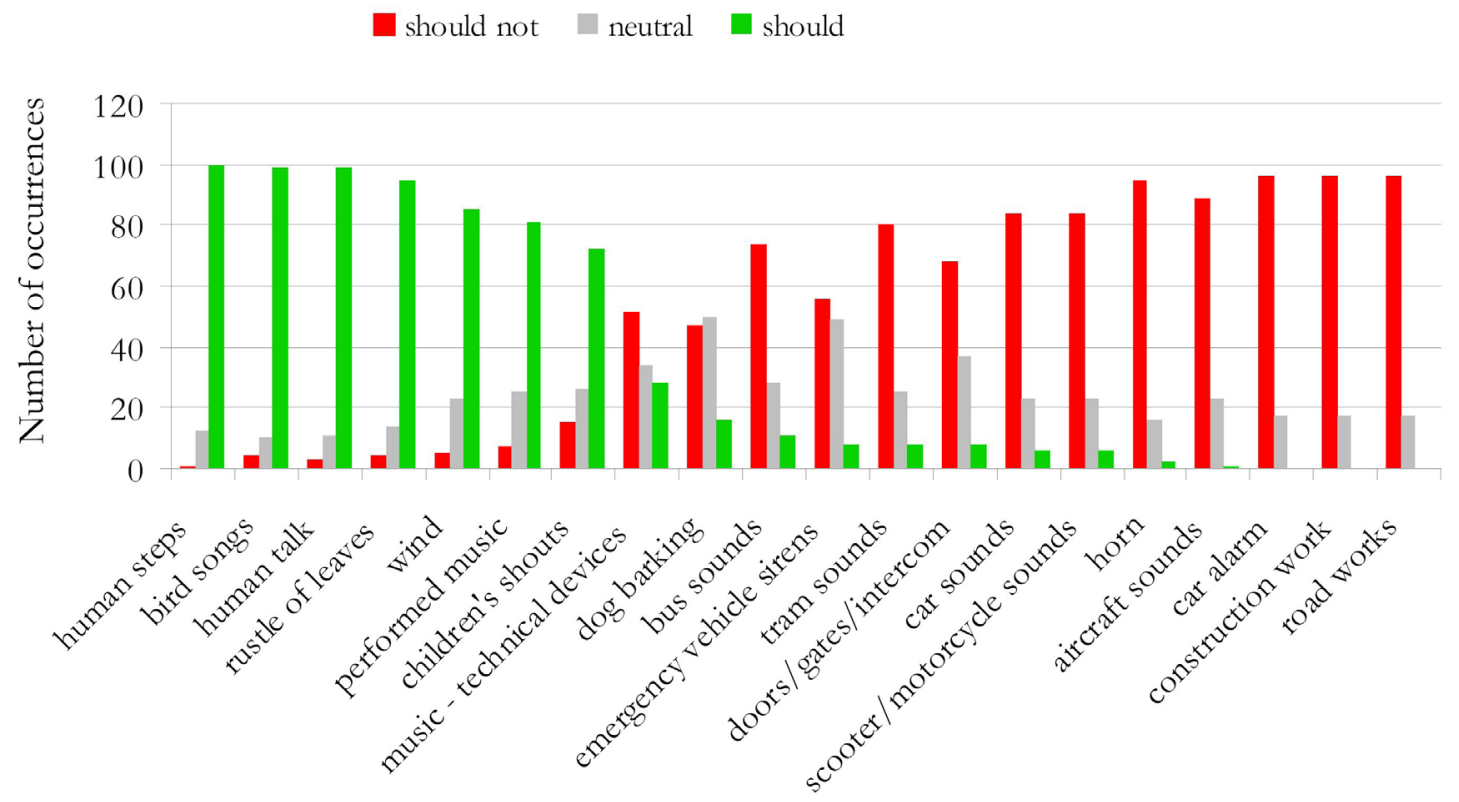

Figure 11. Classification of typical sounds in tourist and recreational areas, on the basis of the survey in Warsaw

(97), car alarm (108), horn (105), bus (101), car (102), tram (99), scooter/motorcycle sounds (103), emergency vehicle sounds (81), and music from technical devices (78). The requirements of the soundscape in open spaces are very high - all mechanical sounds are strongly unwanted (Fig. 15).

Comparing the Figures showing expectations for soundscapes in various urban spaces (Fig. 7, 9, 11, 13, 15), some significant features can be seen. First of all, there is a clearly visible aversion to technological and mechanical sounds, seen in almost all answers about sounds wanted in the environment. This reluctance is not so clear in the case of streets, where rates relating to transport sounds are neutral - and in the case of the city centre, transport sounds are even desirable.
Nature and human sounds are acceptable. Their rates change, but they are always at the forefront of the wanted sounds. In the city centre human sounds should dominate. In tourist areas and streets, nature and human sounds are equally important - there is no dominating category shown in the answers. In residential areas and green spaces, the most desired are nature sounds, then human sounds.

Residential areas and green spaces are interesting because of the similarity of the respondents' opinions about their ideal soundscapes. The only clearly visible difference between these two categories is the rejection of slamming doors/gates/intercom sounds in open spaces and neutral opinions about these sounds in residential areas. Both Figures 5 and 15 are characterized by 

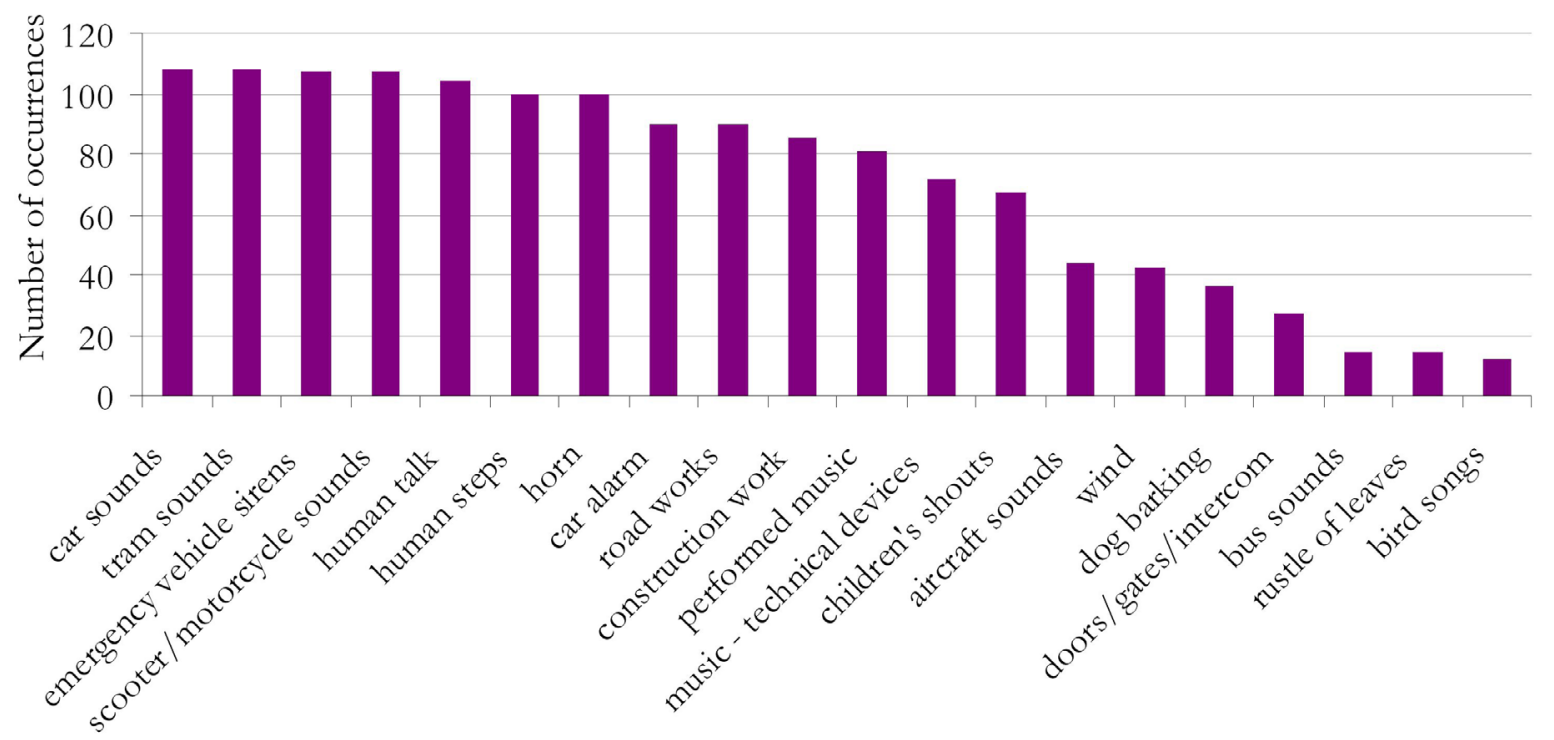

Figure 12. Sounds heard in the city centre, on the basis of the survey in Warsaw

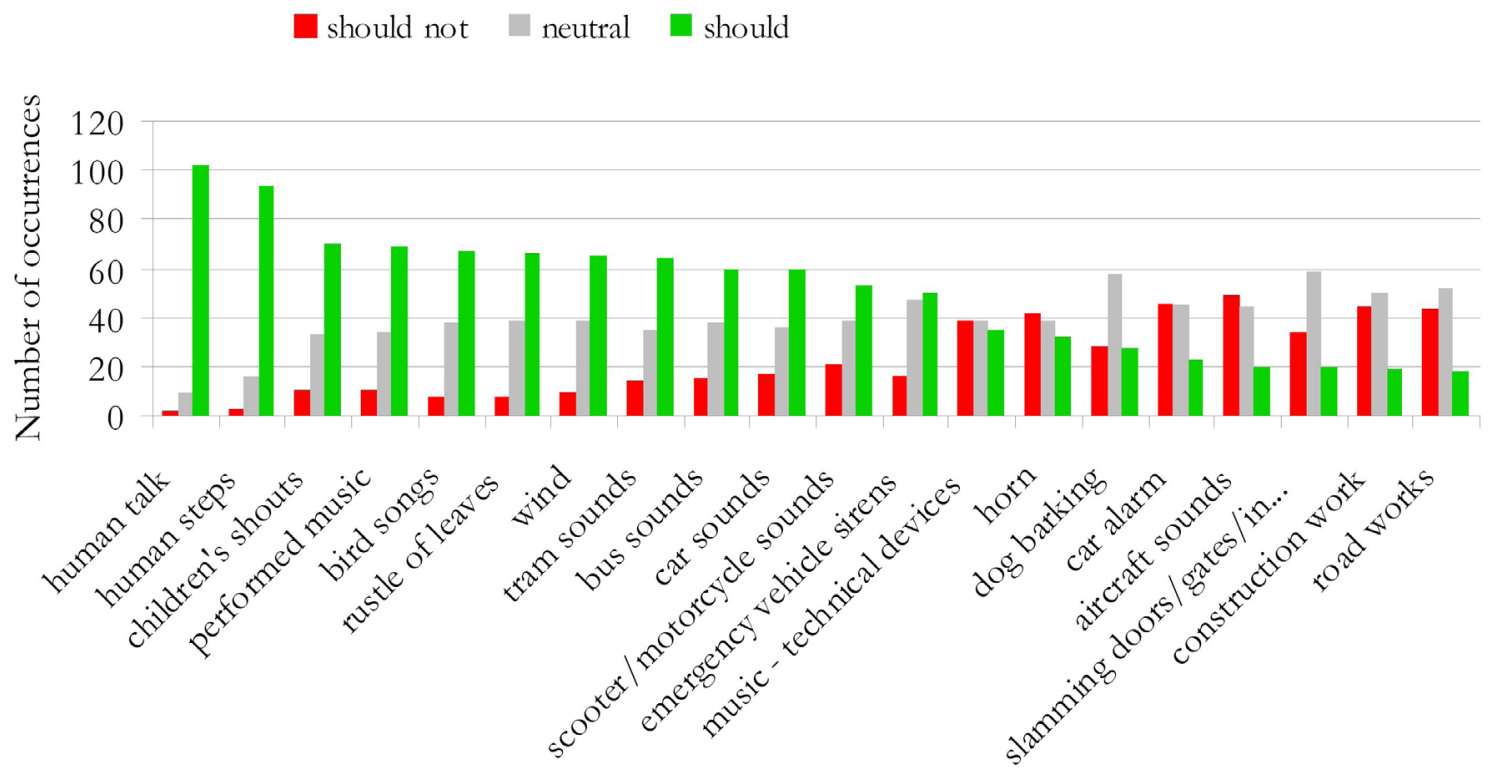

Figure 13. Classification of typical sounds in the city centre, on the basis of the survey in Warsaw

extreme responses - there is a distinct division into two categories - strongly wanted sounds and strongly unwanted sounds. Also, they are characterized by high rates of natural sounds, then human sounds and very low rates of mechanical sounds.

The polarization of responses is seen in Figure 11 (tourist and recreational areas), but there is no domination of nature sounds. Moreover, the Figures relating to streets (Fig. 7) and city centre (Fig. 13) are characterized by the slight fall in the acceptance of different sounds, which means that the residents are tolerant of the structure of soundscapes in those areas.

\section{Warsaw-specific sounds}

The second basic aim of the survey was collecting as much information as possible on the specific sounds of Warsaw. To realize this goal, five questions were asked:
14. Are there sounds in Warsaw which distinguish it from other Polish sites? If so, specify them.

15. Are there sounds in Warsaw which distinguish it from other Polish cities? If so, specify them.

16. Are there sounds in Warsaw which distinguish it from other world metropolises? If so, specify them.

17. Is it important that Warsaw sounds should be specific and stand out among other Polish and global places?

18. Do you have an idea how to make the Warsaw soundscape unique?

The most common answer for the first of these questions was "noise" (and words with similar meaning). The next two most common sounds were subway and tram sounds. Within the first category were sounds of approaching and departing trains, 

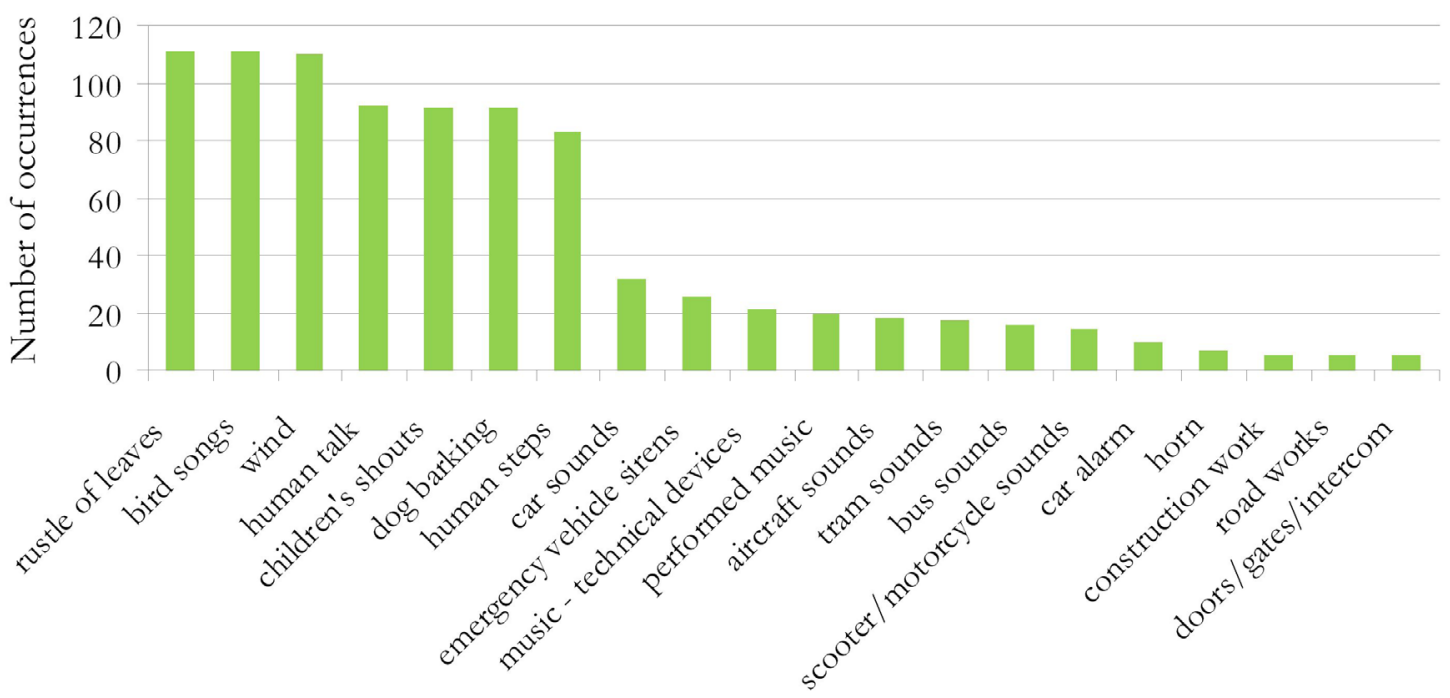

Figure 14. Sounds heard in urban open spaces, on the basis of the survey in Warsaw

should not neutral $\square$ should

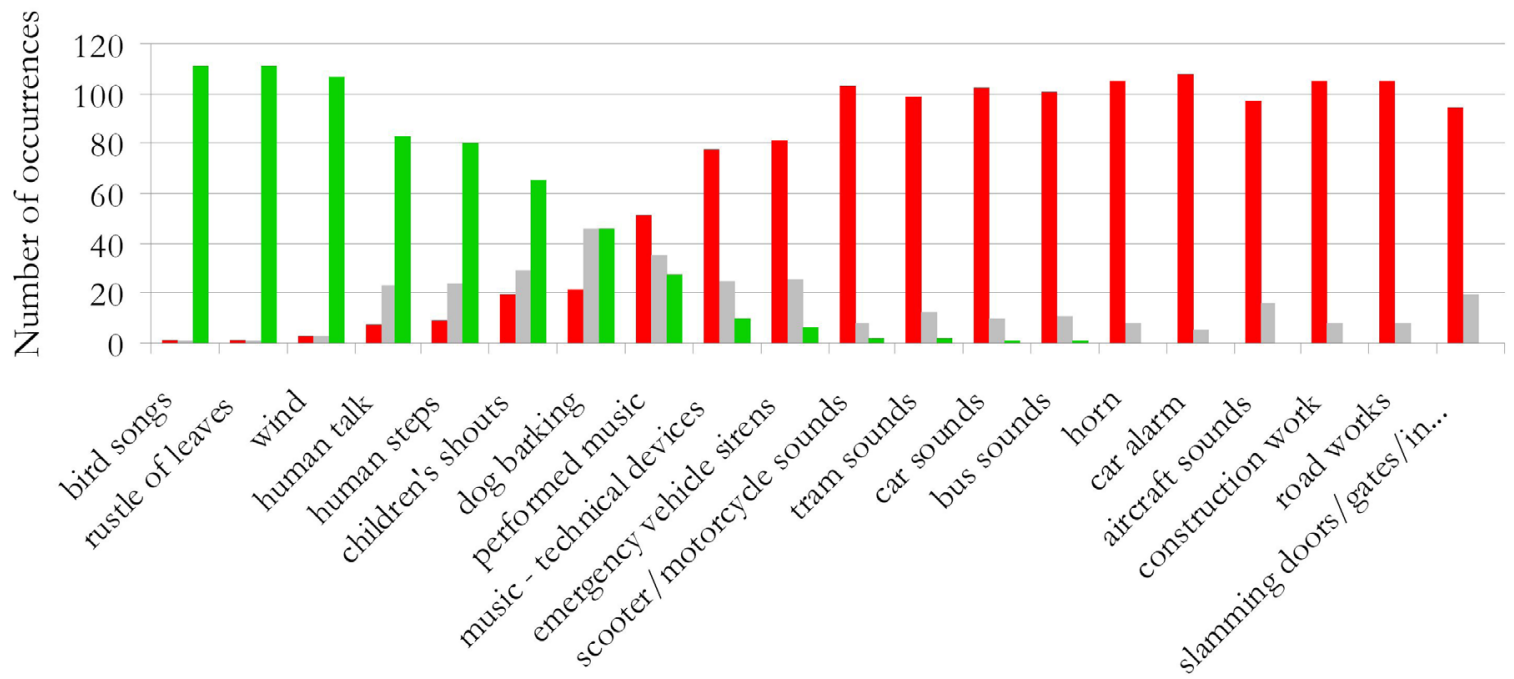

Figure 15. Classification of typical sounds in urban open spaces, on the basis of the survey in Warsaw

rumbling, the voice of the announcer reading station names (Ksawery Jasiński - named by one of the respondents). Within the second category were sounds of moving trams and their characteristic ringing sounds. One of the respondents noticed that in Warsaw the sound of the "sausage" tram has disappeared (in Polish it is called "parówka" - the tram named Konstal 13N, produced in 1959-1969 in Chorzów). Among other answers were: urbanity of the soundscape, music performed in public (i.e. on streets, in trams), all kinds of urban transport sounds, specific "music of the city", conversations in a foreign language, buzz, pickets and protests, compositions in shopping centres, intercom sounds, mobiles, music from electronic devices, concerts, horns, rustle of leaves, bird songs, Chopin's benches, Chopin's concerts in the Łazienkowski Park, sirens on $1^{\text {st }}$ of August, at $5.00 \mathrm{pm}$ (the "W" hour), the Warsaw dialect, the clock at Wola's town hall, the hum of the Vistula River, Bródno Sculpture Park (the "unseen sculpture"), cheering fans, sounds of the cleaning chains of the thermal power plants, sounds of the horse racing at Służewiec, and notification sounds at the Central Railway Station.

The answers for the second question were similar. The most significant differences were the increasing importance of subway sounds, appearance of construction sounds (especially sounds of constructing the second subway line) and decreasing importance of the noise category.

The answers changed when asked about sounds distinguishing Warsaw from other world metropolises. There was only one respondent who replied "the noise". In previous survey questions respondents frequently remarked that Warsaw is noisy. This changed when the city was compared to world cities - in their opinion, Warsaw is quieter than other metropolises. The quiet 
was the most distinguishing feature according to respondents, as well as birds singing on streets and in parks. Quite a lot of people quoted trams, rustle of leaves and performed music. A few of them quoted music from megaphones, horns, music from cars and shops, Chopin's benches, sirens on $1^{\text {st }}$ of August, the announcer on the subway, Bródno Sculpture Park, concerts in the Łazienkowski Park and the harmony of the soundscape.

Despite many noted specific sounds, respondents did not recognize the Warsaw soundscape as identity-building. It is worth noting that most of them did not quote any specific sound distinguishing Warsaw from other Polish cites (65 respondents) and among those who did answer this question, most of them wrote about noise and the subway. Few people listed the most specific elements of Warsaw soundscapes. An analogous situation was found for the next two questions (about sounds distinguishing the city from other Polish cities and from world metropolises).

Intuitively it may seem that specific sounds affect the sense of identity. But responses in the survey suggest that this is not true. In one of the first questions the respondents answered that the Warsaw soundscape should be associated with the term "identity building". In the same survey 70 respondents answered "No, it is not" for the question "Is it important that Warsaw sounds should be specific and stand out among other Polish and global places?". It can be assumed that an identity is not built by specific sounds but by the acceptability and harmony in the city soundscape.

Summing up the part concerning specific Warsaw sounds, the city has a lot of unique sounds, but most residents do not notice them. Most of these sounds are related to particular places and dates. In terms of distinguishable city sounds there are the sounds of the subway, trams and performed music.

According to the quotes, Warsaw is distinguished from other Polish places by being noisy. But, compared with other metropolises, in the respondents' opinions the Warsaw soundscape is quiet, harmonious and full of nature sounds.

There was also a question about ideas for how to make the Warsaw soundscape unique. Ideas included: introduction of quiet and peace, bird songs, performed music, bugle call, hurdygurdy, ingenious announcements of stops on public transport, pleasant sounds on public transport, hum of the Vistula River and surrounding bushes, and sounds of barges and boats sailing on the river. There was a broad category of ideas for playing music from technical devices. There were propositions for playing classical music on public transport and in public places, playing music in various places (adapted to the character of each place), and making public music performances.

\section{Discussion and Conclusion}

The research conducted indicates that the spatial context determines requirements for the soundscape. The general principles tested and described by Guastavino (2006) among others are still relevant: people like nature and human sounds, and dislike mechanical sounds. But the significance of sound categories and tolerance of disliked sounds change depending on the space category. In all space categories, the clearly disliked sounds are construction and road work sounds, car alarm, car horn and aircraft sounds. In urban open spaces and residential areas, mechanical sounds are definitely intolerable, while most desirable are nature sounds as well as human sounds. There is no significant difference between these two space categories. In touristic and recreational areas, nature and human sounds are equally wanted, while mechanical sounds are unwanted. In streets the wanted sounds are similar but in the category of mechanical sounds there is no dominant opinion - they are not clearly undesirable. Some of them are even quite desirable (e.g. tram sounds). In the city centre all sound categories are wanted. The most desirable are human sounds, then nature sounds and mechanical sounds are quite desirable (except for construction and road work sounds, car alarm, car horn and aircraft sounds).

Warsaw is perceived as noisy. Producing free associations, a large part of respondents described its soundscape negatively. This distinguishes Warsaw from other Polish cities (in the opinion of Varsovians). But compared to other world metropolises, respondents regard Warsaw as quite quiet. There are several specific sounds in Warsaw, but only a few people notice them.

There is some reference in the literature to ideal soundscapes and the perception of sounds. In accordance with previous research, people generally prefer nature sounds and human sounds, while mechanical sounds are unpleasant (Zhang \& Kang 2007; Dubois, Guastavino \& Raimbault 2006; Kowalczyk 2008; Guastavino 2006; Nilsson 2007). Compared to the research on the Warsaw soundscape, the general principle holds true, but it is modified to the function of a space. People expect that places where they want to relax should have a quiet soundscape - i.e. residential areas or open spaces - and these are close to the 'basic' ideal soundscape. Their requirements are lower in the case of spaces where certain activities are connected to a specific function. This observation is in accordance with Maffei (2008), who claims that sound ratings are based on expectations. His research in Naples concludes that a positive sound evaluation can be increased by human sounds, if they are in connection with the local culture and history. This fits in with the thesis that there is not only one ideal soundscape - there are many possible alternatives, based on local specifics. This argument is also confirmed by López Barrio \& Carles (1995), who examined Madrid's soundscape and discovered that it cannot be treated as one, fixed for the whole city. There are a number of soundscapes, each with a specific sound environment. They claim that context and sound are strongly interrelated - the meaning of sounds depends on the place where they are heard. Sounds induce various emotional states - and this builds their symbolic meaning.

The results also indirectly confirm the research of Nielbo, Steele \& Guastavino (2013). They found that people rate soundscapes through activities. In the Warsaw research, certain space categories are related to human activities. The relation between the space category and human preferences does not deny the existence of other factors affecting the perception of the soundscape. In fact it proves the complexity of the variables which influence subjective impression.

Kowalczyk (2008) examined the hierarchy of nature sounds, which is similar to the hierarchy resulting from the Warsaw research. Above all, people prefer bird songs, then water sounds, rustle of leaves and wind. Except for water sounds (this group was not included in the Warsaw survey), the results are congruent.

An interesting outcome repeated in much of the research (Kowalczyk 2008; Guastavino 2006; Zhang \& Kang 2007) refers to music. People rate music performed by other people in public places positively, but their attitude to music from technical devices is quite negative. In the Warsaw research these observations were confirmed. But it should be noticed that a few people proposed playing recorded music in public places in Warsaw. They probably think that music chosen by sound designers would be more pleasant (in contrast to random songs heard from cars or shops).

There are two categories of listening to traffic sounds (Zhang \& Kang 2007): holistic hearing (without semantic processing, 'background noise') and descriptive listening - containing an identification of sources or events. In accordance with Guastavino (2006), background noise is generally better accepted than source events. This is clearly seen in the results of the Warsaw survey: among mechanic sounds, those which can contribute to background noise (car, bus and tram sounds) are better rated than those which are distinct signals (horn, car alarm). 
Guastavino also claims that public transport noise is more acceptable than personal vehicle noise. This is probably the result of cognitive processes - public transport is more socially acceptable and environmentally friendly. The Warsaw research confirms this thesis.

It is important to discuss the relation between sound level and pleasantness. Zhang \& Kang (2007) say that sound pressure level is poorly related to acoustic evaluation when its value is below 65-70 dB. In the Warsaw research, many people claim that the city is noisy. In analysing the Warsaw acoustic map it can be seen that there are many areas with more than $65 \mathrm{~dB}$ daily average sound pressure level. Managing the Warsaw soundscape must be executed in parallel with decreasing sound level. When sound level is low enough, then many other factors have a huge impact on perception of the soundscape (Cain et al. 2008). This is in accordance with Lewandowski \& Szumacher (2008), who conducted surveys to find out which places, evaluated as having the same sound level, have different pleasantness ratings.

According to Berglund, Nilsson \& Axelsson's (2007) research, there are two main factors affecting sound perception: 'Pleasantness' and 'Eventfulness'. Eventful and pleasant soundscapes are exciting. Eventful but unpleasant are chaotic. Unpleasant and uneventful are boring. Pleasant and uneventful are relaxing. According to responses to the question about terms describing the Warsaw soundscape (Fig. 4), it is eventful, chaotic, unpleasant, not stimulating and not exciting. In the model made by Berglund, Nilsson \& Axelsson, an eventful soundscape is exciting when human sounds are dominant. The domination of mechanical sounds makes the soundscape less stimulating, unpleasant and chaotic - these soundscapes are probably mostly present in Warsaw. The Warsaw soundscape, in the view of the respondents, is not relaxing, boring or soothing - which means that it is definitely eventful.
Still, based on Berglund, Nilsson \& Axelsson, it is easy to analyse the functions of space categories. Soundscapes where nature sounds dominate are relaxing; human sounds dominate in exciting soundscapes. The Warsaw respondents expect that the most common sounds in green spaces and residential areas will be nature sounds. In the city centre and tourist areas there should be human sounds. This means that residential areas and parks should have a relaxing function, the city centre and tourist areas an exciting one.

These findings are relevant for urban planning. Dominant sounds should be related to the function of a particular place. Generally, traffic and mechanical sounds should be reduced in residential areas, open spaces, tourist and recreational areas. Highways and other main streets should be conducted far from those spaces or should be isolated (e.g. by creating a frontage of non-residential buildings). Traffic sounds should sound like a quiet hum. The architecture and vegetation of these places should invite birds to live there. The organization of space should also encourage people to realize certain activities and introduce human sounds.

In streets and city centres reducing mechanical sounds is not so important - people accept them, because they correspond to the function of the place. But mechanical sounds should not be obviously dominant. In the streets and city centre there are not enough human and nature sounds. The space is dominated by cars, buses and trams. The challenge for urban planners is to make the urban space friendlier for people and other beings. Then, the varied soundscape would be evidence of a rich street life.

There is no single, universal soundscape. It changes as the space changes. There are some general rules, but every case needs individual treatment. It is always related to other aspects of space, other senses, human activities, experiences and culture.

\section{References}

Brambilla, G, Gallo, V, Asdrubali, F \& D'Alessandro, F 2013, 'The perceived quality of soundscape in three urban parks in Rome', The Journal of the Acoustical Society of America, vol. 134 , no. 1 , pp. $832-839$.

Berglung, B, Nilsson, ME \& Axelsson, Ö 2007, 'Soundscape psychophysics in place' in Inter-noise 2007, Instanbul, 28-31 August 2007.

Cain, R, Jennings, P, Adams, M, Bruce, N, Carlyle, A, Cusack, P, Davies, W, Hume, K \& Plack, CJ 2008, 'Soundscape. A framework or characterising positive urban soundscapes', The Journal of the Acoustical Society of America, vol. 123, no. 5, pp. 3394.

Dubois, D, Guastavino, C \& Raimbault, M 2006, 'A cognitive approach to urban Soundscapes. Using verbal data to access everyday life auditory categories', Acta Acustica united with Acustica, vol. 92, no. 6, pp. 865-874.

Gradowski, M 2004, 'R. Murray Schafer - pan od przyrody?', Glissando, vol. 2, pp. 58-61.

Guastavino, C 2006, 'The ideal urban soundscape. Investigating the sound quality of French cities', Acta Acustica united with Acustica, vol. 92, no. 6, pp. 945-951.

Ipsen, D 2002, The Urban Nightingale or some theoretical considerations about sound and noise. Available from: $<$ http://www.uni-kassel.de/fb6/AEP/pdf/nightingale.pdf>. [21 December 2013]

Jespersen, MR 2001, Soundtrekking soundscapes. Available from: <http://wfae.proscenia.net/library/articles/jespersen \%20_\%20soundtrekkingpdf.pdf>. [21 December 2013]

Kang, J 2007, Urban Sound Environment, Taylor \& Francis incorporating Spon, London.
Kowalczyk, A 2008, 'Preferencje dźwięków w krajobrazie' [Sound preferences in a landscape; in Polish] in Dźwięk w krajobrazie jako przedmiot badań interdyscyplinarnych, ed S Bernat, Prace Komisji Krajobrazu Kulturowego PTG, Lublin, vo. 11, pp. 36-43.

Lewandowski, W \& Szumacher, I 2008, 'Dźwięk jako walor krajobrazu' [Sound as a landscape advantage; in Polish] in Dźwięk w krajobrazie jako przedmiot badań interdyscyplinarnych, ed S Bernat, Prace Komisji Krajobrazu Kulturowego PTG, Lublin, vol. 11, pp. 54-62.

López Barrio, I \& Carles, J 1995, 'Madrid - acoustic dimensions of inhabited areas. Quality criteria', The Soundscape Newsletter, vol. 10, pp. 10-13.

Maffei, L 2008, 'Urban and quiet areas soundscape preservation' in Proceedings of VI Congreso Iberoamericano de Acustica - FIA 2008, Buenos Aires.

Neilbo, F, Steele, D \& Guastavino, C 2013, 'Investigating soundscape affordances through activity appropriateness' in Proceedings of ICA 2013, Montreal, vol. 19.

Nilsson, ME 2007, 'Soundscape quality in urban open spaces' in Inter-noise 2007, Instanbul.

Romanowska, M 2013, Krajobrazy dźwiękowe Warszawy struktura i specyfika [Soundscapes of Warsaw - structure and specific; in Polish], Master's work at University of Warsaw.

Wrightson, K 2000, 'An Introduction to Acoustic Ecology', Soundscape, vol. 1, no. 1, pp. 10-13.

Zhang, M \& Kang, J 2007, 'Towards the evaluation, description, and creation of soundscapes in urban open spaces', Environment and Planning B: Planning and Design 2007, vol. 34, pp. 68-86. 